\title{
OPEN Self-care tooling innovation in a disabled kea (Nestor notabilis)
}

\begin{abstract}
Amalia P. M. Bastos ${ }^{1,5}$, Kata Horváth ${ }^{2}{ }^{2,3,4,5}$, Jonathan L. Webb ${ }^{1}{ }^{1}$, Patrick M. Wood ${ }^{1}{ }^{1} \&$ Alex H. Taylor ${ }^{1}$

Tooling is associated with complex cognitive abilities, occurring most regularly in large-brained mammals and birds. Among birds, self-care tooling is seemingly rare in the wild, despite several anecdotal reports of this behaviour in captive parrots. Here, we show that Bruce, a disabled parrot lacking his top mandible, deliberately uses pebbles to preen himself. Evidence for this behaviour comes from five lines of evidence: (i) in over $90 \%$ of instances where Bruce picked up a pebble, he then used it to preen; (ii) in $95 \%$ of instances where Bruce dropped a pebble, he retrieved this pebble, or replaced it, in order to resume preening; (iii) Bruce selected pebbles of a specific size for preening rather than randomly sampling available pebbles in his environment; (iv) no other kea in his environment used pebbles for preening; and ( $v$ ) when other individuals did interact with stones, they used stones of different sizes to those Bruce preened with. Our study provides novel and empirical evidence for deliberate self-care tooling in a bird species where tooling is not a species-specific behaviour. It also supports claims that tooling can be innovated based on ecological necessity by species with sufficiently domain-general cognition.
\end{abstract}

Tooling-deliberately generating a mechanical interface by using an object to manipulate another target or surface $^{1,2}$-is a complex embodied form of tool use which has been documented in only a few species ${ }^{1,3,4}$. When tooling, an animal and the tooling object are transformed into a single body-plus-object system ${ }^{1,2}$, performing contextually appropriate, embodied problem-solving ${ }^{1,2,5}$. Flexible tool use, including tooling, often emerges in the form of behavioural innovations, where animals develop a novel behaviour in response to situational changes ${ }^{6}$. Tool use behavior-including but not limited to tooling-has been regarded as a marker of complex cognition across birds and mammals ${ }^{4,7,8}$, a link which has led to considerable interest in the field ${ }^{3,9-12}$. Within birds, flexible tooling has been found most commonly in clades with large relative brain sizes, such as corvids ${ }^{3,9-11,13-18}$ and parrots $3^{3,10,19-23}$.

Most reports of tooling in birds revolve around foraging ${ }^{9-12,14,15,20,21,23-25}$. Among parrots this is more common in captive settings, for example, greater vasa parrots use small stones to scrape or break up shells, which they then ingest ${ }^{23}$, hyacinth macaws use wedges to manipulate nuts ${ }^{20}$, and Goffin's cockatoos innovate and manufacture stick tools to retrieve out-of-reach food ${ }^{19}$. Despite not habitually using tools in the wild, kea parrots (Nestor notabilis) learn to insert sticks and other objects into traps designed for pest species such as stoats ${ }^{21}$, which allows them to safely access egg bait placed inside. Kea also probe at and set off unbaited traps, an apparently non-functional behaviour which may be playful or exploratory in nature ${ }^{21}$. In captivity, kea also readily learn to use stick tools for extractive foraging in experimental settings $\mathrm{s}^{26,27}$.

In the wild, tooling in a self-care context appears to be rarer than in foraging contexts ${ }^{28,29}$. However, there are anecdotal and video reports of several parrot species innovating self-care tooling in captivity, primarily by holding sticks or other objects with their feet to scratch themselves, 90,30 . These behaviours have not been rigorously reported in the literature and so it is unclear how they were innovated, how frequently they occur, or if reduced interactions with conspecifics in captivity reduces allopreening and so drives the individual innovation of self-care tooling.

Recently, a study reported self-care tool use in Atlantic puffins (Fratercula arctica), which were observed holding sticks to their bodies, possibly in order to scratch themselves ${ }^{28}$. This claim rests on two observations across four years of two puffins living in colonies over $7000 \mathrm{~km}$ apart (in Wales and Iceland), for which only one tool use instance was recorded on video. This claim has garnered significant attention from the scientific

\footnotetext{
${ }^{1}$ School of Psychology, The University of Auckland, Private Bag 92019, Auckland 1142, New Zealand. ${ }^{2}$ Doctoral School of Psychology, ELTE Eötvös Loránd University, Izabella Utca 46, 1064 Budapest, Hungary. ${ }^{3}$ Institute of Psychology, ELTE Eötvös Loránd University, Izabella Utca 46, 1064 Budapest, Hungary. ${ }^{4}$ Brain, Memory and Language Research Group, Institute of Cognitive Neuroscience and Psychology, Research Centre for Natural Sciences, Magyar tudósok körútja 2, 1117 Budapest, Hungary. ${ }^{5}$ These authors contributed equally: Amalia P. M. Bastos and Kata Horváth. ${ }^{\circledR}$ email: a.bastos@auckland.ac.nz
} 


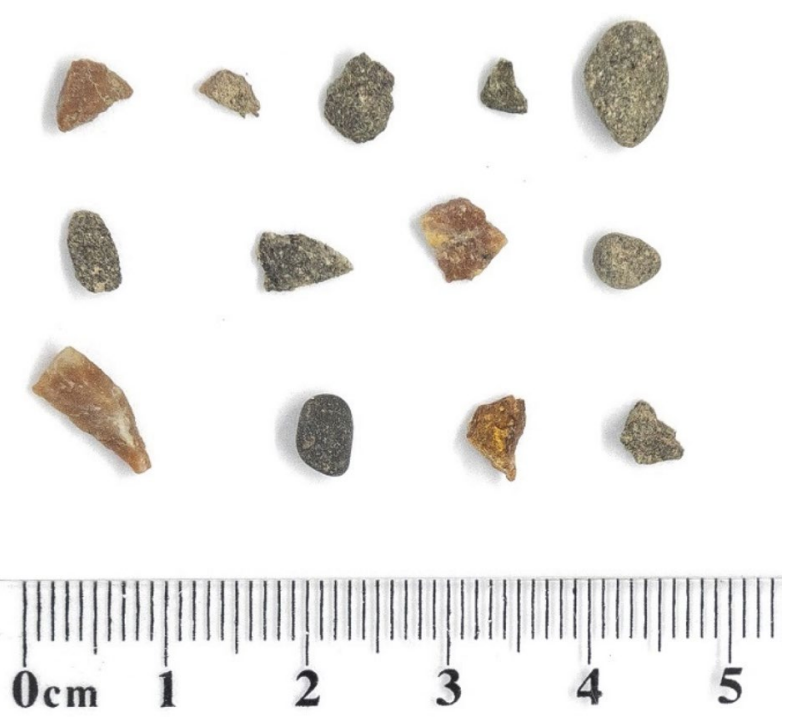

Figure 1. Photographs of pebbles Bruce manipulated and preened with which could be retrieved by the experimenters. Tools were retrieved by the experimenters only after Bruce dropped them.

community, which has been skeptical that the study provides sufficient evidence of tool use ${ }^{31-35}$. Not only is the single recorded incident short in duration, lasting approximately one second, but the touching of the stick to the puffin's chest may have been an accidental combination of two other behaviours, namely holding a stick and attempting to scratch itself ${ }^{31,34}$. Critics of this study ${ }^{31-35}$ have argued for a hypothesis-testing approach to anecdotal reports such as these, suggesting that convincing evidence for tool use in puffins should include: (i) comparisons between the number of instances where sticks are picked up and used for scratching, and instances where they are picked up but not used for scratching; (ii) evidence of subjects' intention to scratch with a stick, for example by showing that they exhibit preferences for sticks with favorable characteristics, value previously useful tools, or perform the same behaviour repeatedly over multiple days; and (iii) comparisons between toolusing and non-tool-using individuals, where the latter should be more likely to pick up sticks without performing scratching actions than the former.

These criticisms are pertinent to our observations of apparent innovation of self-care tooling by a disabled kea parrot, a species where tooling is not a species-specific behaviour. Bruce, a wild-born male with an estimated age of 8 years, is disabled due to him missing the upper part of his bill. This means that he struggles to perform basic functions kea use their powerful beaks for, such as eating and preening. Bruce appears to use small pebbles (which he typically takes from a gravel path in the aviary, using his lower mandible to scoop them up) to preen himself. Pebbles are wedged between his lower mandible and tongue, and moved along his feathers. This appears analogous to other subjects' clasping and grinding of feathers between their upper and lower mandibles.

Here, we aim to provide evidence for Bruce's deliberate self-care tooling behaviour from repeated observations, by creating a scientifically rigorous way to report self-care tooling. In line with critiques of the puffin report, we hypothesize that this behaviour could be considered deliberate rather than incidental if our data indicate that: (i) Bruce's instances of pebble manipulations occur simultaneously with preening more often than not; (ii) he performs this preening tooling behaviour repeatedly and specifically with pebbles, retrieving or replacing lost preening pebbles; (iii) he uses pebbles with particular characteristics which can afford this preening function; (iv) he preens with a pebble more often than other individuals with typical beak morphology housed in the same aviary, who should be less likely than him to combine object manipulation and preening behaviours into a single action; and (v) the types of objects he interacts with are different to those selected by other individuals, who do not use pebbles as preening tools.

\section{Results}

Do Bruce's pebble manipulations co-occur with preening? Bruce's pebble manipulations typically began with rolling a small pebble (Fig. 1) around with his tongue. He then wedged the pebble in his lower bill, and either rolled it or ran it along his feathers, which were held between the pebble and his tongue (Supplementary Video). This latter motion appears analogous to other subjects' clasping and grinding of feathers between their upper and lower bills (Supplementary Video), which helps remove ectoparasites lodged between their barbs $^{36}$.

We first examined whether or not Bruce's pebble manipulations were followed by preening. Across $20 \mathrm{~h}$ of video observations recorded over 9 days, we recorded 30 videos where Bruce picked up a pebble and subsequently preened with it at least once (93.75\% of cases), while there were only two instances where he picked up a pebble and did not preen with it for the duration of that observation. In one of these two instances, Bruce picked up a pebble and then took part in an aggressive display against another male, subsequently dropping it. In the other, he attempted to preen with the pebble but dropped it, then began interacting with another male. The frequency 


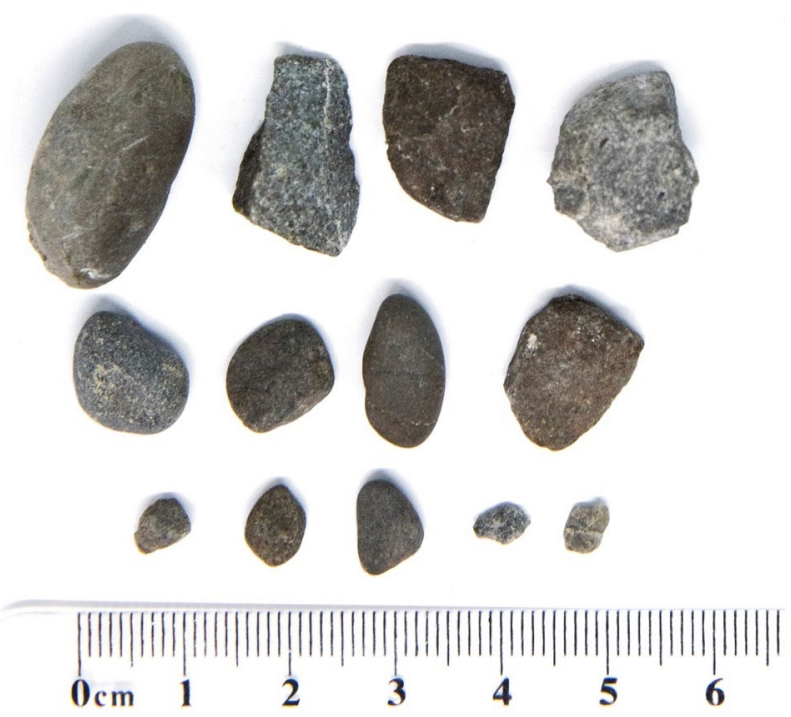

Figure 2. Photographs of pebbles and stones randomly sampled from the aviary by the experimenters.

of his pebble interactions and preening behaviours provides strong evidence that Bruce's preening behaviour was associated with his pebble manipulations; namely, when he interacted with a pebble, he was 1579.72 times more

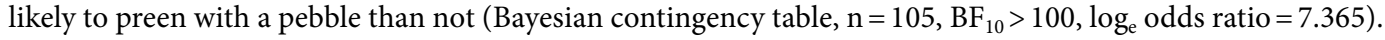

Are pebble tools valuable and effective to Bruce? To determine whether Bruce's pebble tooling was deliberate, we examined whether he attempted to retrieve or replace preening pebbles that he dropped during preening. We recorded 250 events where he dropped his preening pebble and subsequently retrieved or replaced it before he resumed preening, out of a total 262 retrieval and replacement events $(95.42 \%)$. It is also notable that all pebbles used were similar in size $\left(19.70 \pm 9.14 \mathrm{~mm}^{2}\right.$; Fig. 1$)$, suggesting that his choice of pebble tools was deliberate and functional. To test this, we compared the pebble sizes Bruce used to a random sample of pebbles and stones in his environment $\left(98.39 \pm 75.62 \mathrm{~mm}^{2}\right.$; Bayesian independent samples t-test, $\mathrm{BF}_{10}=29.41$; Fig. 2). This suggests that Bruce deliberately selected very small pebbles relative to the population of pebbles and stones present in the aviary.

In total, we observed 103 preening episodes by Bruce, with 30 involving a pebble and 73 not involving a pebble. This raises the question of whether Bruce preferred to preen with a pebble only in certain contexts. To this end, we compared the percentage of the time he spent preening different parts of his body (divided into wings, back, neck, chest, legs, and tail) with and without a pebble tool. Bruce employed pebbles for preening differentially throughout his body (Bayesian contingency table test, $\mathrm{BF}_{10}>100$; Supplementary Table 4). He preened most of his body parts without a pebble more frequently than with a pebble (wing: $29.72 \%$ vs. 9.94\%; back: $8.39 \%$ vs. $5.00 \%$; neck: $6.33 \%$ vs. $1.44 \%$; chest: $11.22 \%$ vs. $3.33 \%$; tail: $2.56 \%$ vs. $1.11 \%$ ). However, he preened his legs without a pebble only $5.78 \%$ of the time, but with the pebble this constituted $15.17 \%$ of all observed preening behaviours suggesting that this body part was a specific focus of his pebble preening.

Finally, we compared the time Bruce spent preening with and without a pebble, to establish whether pebble use affected his preening time. Bruce preened himself for slightly longer with a pebble than without one (Bayesian independent samples t-test, $\mathrm{BF}_{10}=1.26$; with a pebble: $176.15 \pm 208.51 \mathrm{~s}$, without a pebble: $114.28 \pm 133.89 \mathrm{~s}$ ).

How does Bruce's behaviour compare to that of other individuals? We compared Bruce's manipulations of pebbles and non-pebble objects with those of other individuals. We observed no instances of any other subjects preening with pebbles or other objects, despite them regularly manipulating objects for purposes other than preening. Non-preening object manipulations occurred 202 times across eight other subjects (averaging 25.25 \pm 37.53 instances each), compared to 18 times for Bruce. Therefore, Bruce appeared to manipulate non-pebble objects at a comparable or lower rate to other subjects (Supplementary Table 5) but was the only individual that used pebbles as preening tools. Interestingly, the size and types of objects that other subjects interacted with were also different, appearing to favor larger stones and non-pebble objects which were never used for preening (Bruce: $19.70 \pm 9.14 \mathrm{~mm}^{2}$; other subjects: $184.92 \pm 172.15 \mathrm{~mm}^{2}$; Bayesian independent samples t-test $\mathrm{BF}_{10}=18.11$; Fig. 3). This was despite the fact that Bruce can competently hold larger objects (Fig. 4).

\section{Discussion}

We show that kea are capable of innovating self-care tooling, which is rarely seen in birds ${ }^{28,29}$. Our observations suggest that the preening pebble may be used as a flat surface against which Bruce can grind his feathers, such that the tongue and pebble act analogously to the upper and lower bills of other individuals. Bruce's pebble preening behaviour strongly suggests deliberate tooling ${ }^{31-35}$. First, Bruce's manipulations of pebbles were almost always followed by preening, suggesting that he picked up the pebble with the intent of using it as a preening 


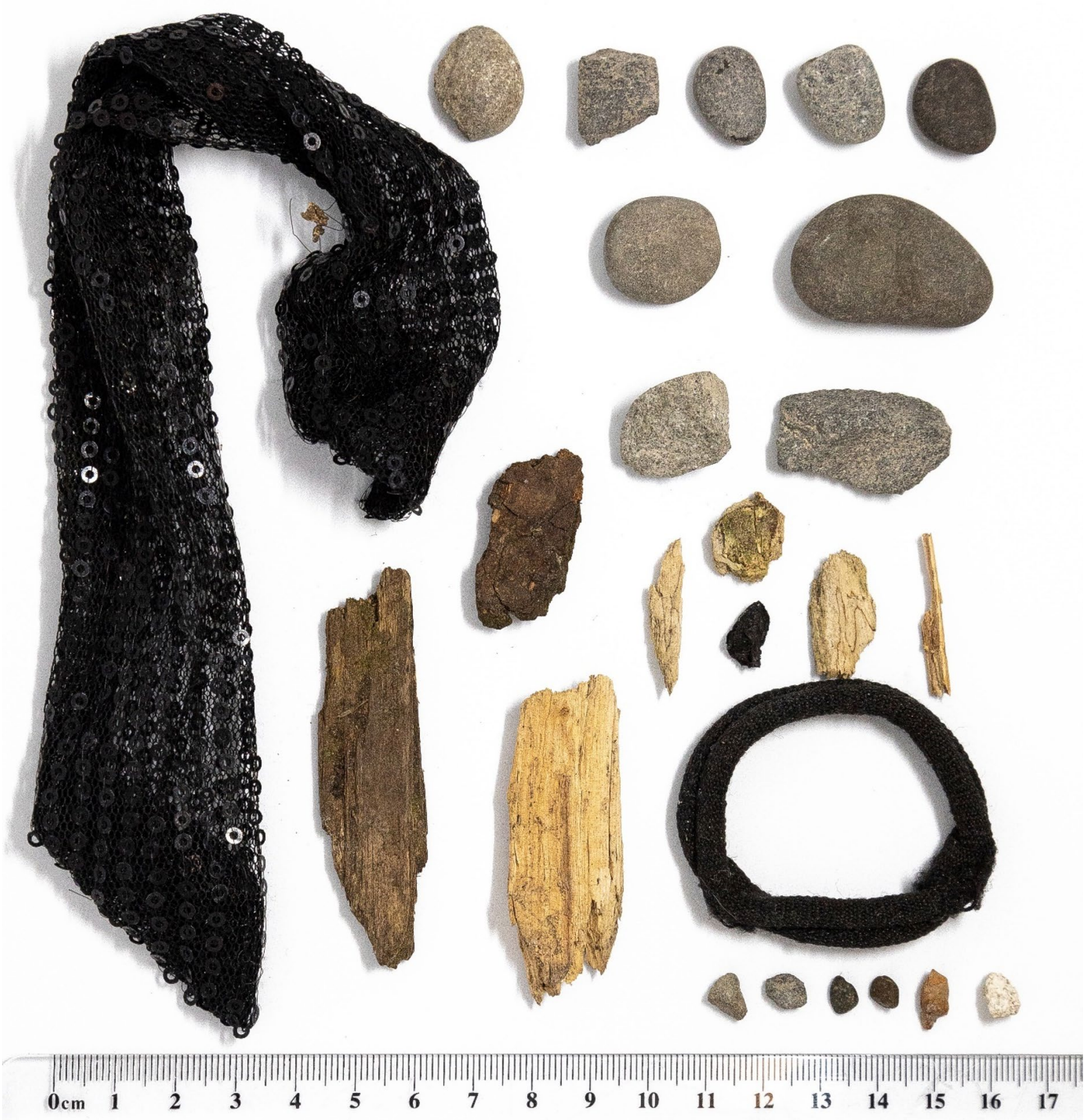

Figure 3. Photographs of objects that subjects other than Bruce interacted with and subsequently dropped, which experimenters were able to retrieve. There were no instances of these subjects preening whilst manipulating any objects.

tool. Second, Bruce often retrieved or replaced pebbles he lost or dropped, suggesting that he valued the pebble tool during preening. Third, Bruce selected pebbles of a particular size for use as tools, given that his pebble tools differed in size significantly from a randomly drawn sample of stones available in his environment. Fourth, while Bruce manipulated non-pebble objects at a similar rate to other individuals, he was the only subject ever observed preening with a pebble. Finally, when other did interact with stones and pebbles, they were significantly greater in size than those selected by Bruce. We therefore show that Bruce innovated pebble preening as a selfcare tooling behaviour, likely as a direct consequence of his disability, by systematically testing the predictions for deliberate tooling in a bird species where tooling is not a species-specific behaviour.

Within the framework of tooling ${ }^{1}$, Bruce's pebble preening can be described as an egocentric (self-directed) behaviour, with a single dynamic relation between the tool and his feathers or skin. The placing of the pebble is probably crucial to its functional use. Given that Bruce often repeatedly moves the pebble until he rests it on his lower mandible before he begins to preen with it, it is possible that its orientation is also important. However, this could also serve the purpose of lodging it comfortably within the mandible, unrelatedly to the function of the pebble. It is unclear if the alignment of the pebble is important. The properties of Bruce's pebble tooling may therefore be different to those observed in foraging stick tooling by both kea and other parrot species ${ }^{19,21,26,37}$, 

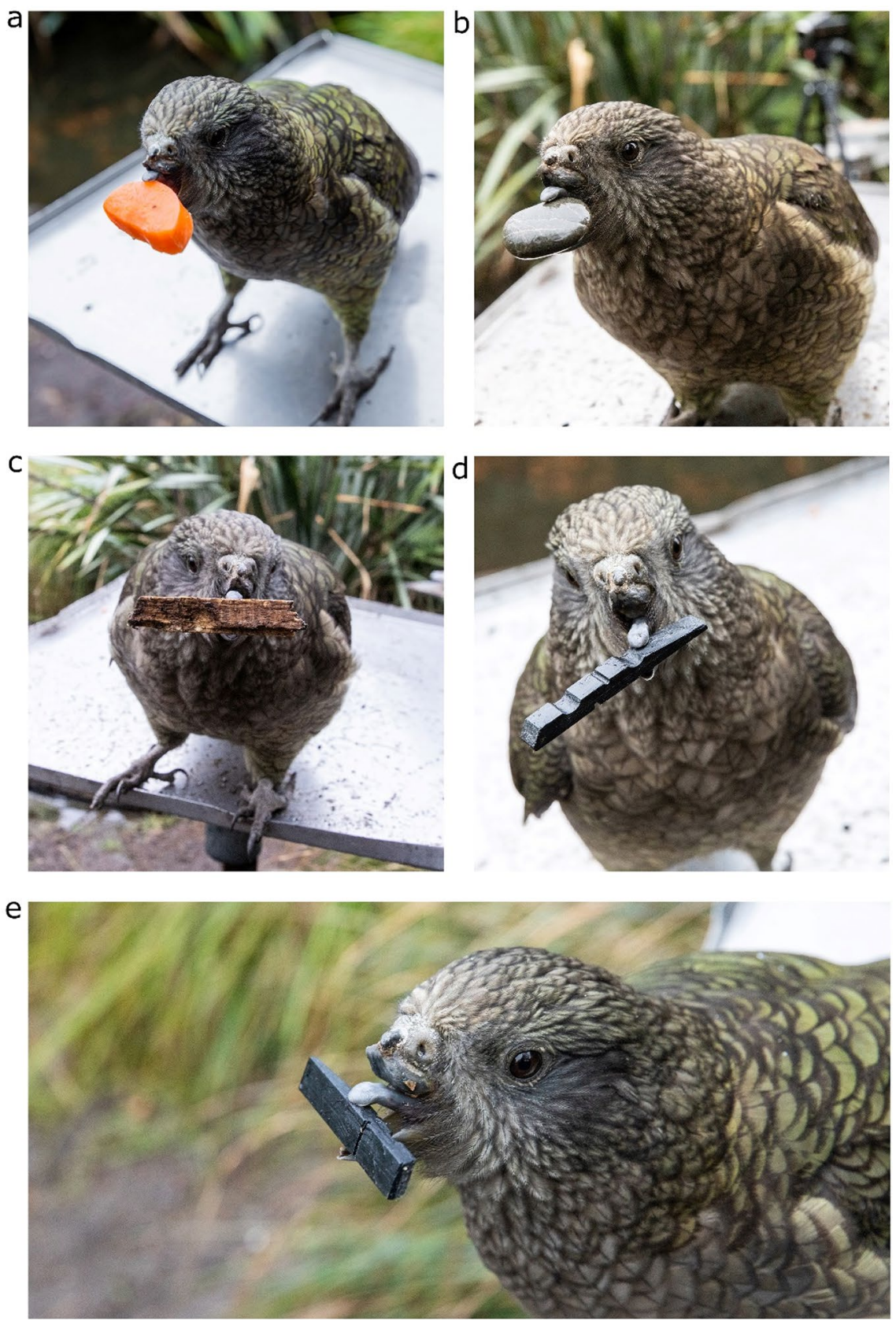

Figure 4. Photographs of Bruce handling objects larger than his preening pebbles, namely: (a) a slice of carrot, (b) a stone, (c) a piece of bark, (d) a black token used in previous cognitive experiments he was a part of. We also provide a close-up image in (e) demonstrating how he uses his tongue and lower mandible to hold these objects.

which is allocentric and alignment-crucial, and the egocentric self-care tooling observed in a range of captive parrot species ${ }^{9,10,30}$. Further research is needed to investigate this possibility.

Our results suggest that Bruce's tooling is flexible and deliberate. Evolved stereotyped tooling is innate, involving fixed action patterns that cannot be adapted to novel situations ${ }^{4,38}$. It is highly unlikely that Bruce's pebble use is an evolved stereotyped action, given that, to the best of our knowledge, it is unique to him as an individual, and therefore likely a flexible, context-dependent innovation. Furthermore, Bruce does not attempt to preen with objects of a similar size in his environment to the pebble tools or with larger stones, as might occur with a fixed action pattern, despite being able to competently hold larger objects either between his tongue and lower bill, or between the remnants of his upper bill and lower bill.

It is unclear if the pebble tool employed by Bruce improves his preening efficiency, or whether it is adopted for some other function, given that preening episodes with the pebble were longer than those without. It might be that the pebble tool improves preening efficacy but not efficiency, for example by providing increased success in dislodging parasites at the cost of greater time expenditure. Bruce appeared to be selective in terms of the properties of the pebbles he chose, given both that he discarded some pebbles before attempting preening 
with them, and our data showing that he did not randomly sample from the environment. Precisely what pebble properties Bruce based his decisions on will be a focus of future work.

Together with kea's other tooling innovations reported in the wild ${ }^{21}$ and in captivity ${ }^{26}$, Bruce's deliberate selfcare tooling suggests that kea may excel at innovating context-appropriate tools. This provides additional evidence for kea's highly flexible problem-solving abilities, as evidenced in previous experiments including both captive and wild populations ${ }^{21,26,27,37-42}$. The ability to flexibly combine information in a domain-general manner ${ }^{43}$, when combined with playfulness and neophilic exploration of the environment, may be an important driver of technical innovations in kea and other species ${ }^{44,45}$. These results therefore support recent claims that tool use, including tooling, arises not only from the evolution of specialized physical cognition ${ }^{46-49}$, but can be innovated, when ecologically necessary, by species with sufficiently domain-general cognition ${ }^{21,47-49}$.

\section{Materials and methods}

Subjects and procedures. All observations were of a captive population of kea (Nestor notabilis) housed in a large, naturalistic outdoor aviary at Willowbank Wildlife Reserve in New Zealand. This population comprised thirteen individuals ( 10 males, 3 females) with ages ranging from 8 months to 25 years (Supplementary Table 1). Food and water were available ad libitum, and subjects were free to behave and interact normally in their environment throughout observation sessions. Observation sessions were at least one hour long and took place in the mornings, when birds were most active. This research was conducted under ethics approval from The University of Auckland Ethics Committee (reference number 001816). The study was also carried out in accordance with the relevant guidelines and regulations.

Observations took place in two stages. The first stage involved $20 \mathrm{~h}$ of focal observations of Bruce over nine days, where any interactions with objects and any preening episodes were recorded on video, until $30 \mathrm{~s}$ after the end of the preening or object manipulation episode. In every preening episode, experimenters either approached Bruce or zoomed in with their video camcorders to establish if an object was being held in his beak during the preening episode. This was unlikely to affect his behaviour, given that Bruce was familiar with all four experimenters and has an extensive history of participating in cognitive studies where he stands in close proximity to humans ${ }^{40,43,50}$. Bruce's preening episodes were never interrupted, so that we could compare the total length of preening episodes with and without pebbles to assess whether pebble use affected preening efficiency.

The second stage involved $20 \mathrm{~h}$ of observations of the remaining 12 subjects in the aviary, over thirteen days. The experimenters watched the group and, whenever an individual began to preen or interact with objects, these episodes were recorded on video. At the end of each preening episode, or after two minutes of preening (whichever occurred first), the subject was interrupted and offered a black token, which they could exchange for a piece of food. This was done to inspect the subject's mouth for any objects. We did not record entire preening episodes for other subjects, as we did not plan to compare the length of their preening episodes to Bruce's. Most importantly, the observation of the other subjects allowed the experimenter to verify whether the subject had been holding any objects in their beak as they preened. Where the subject was perched out of reach, the video was zoomed into its beak until the experimenter could determine whether the subject was holding an object in its beak.

Wherever possible, across both observation stages, experimenters attempted to retrieve any objects subjects interacted with, either for preening or during other object manipulation behaviours. Experimenters also collected thirteen randomly selected pebbles and stones from across the aviary which were smaller than or equal to the largest stone manipulated by kea during our observation sessions. To ensure that pebbles were selected randomly, we drew a map of the aviary divided into $1 \mathrm{~m}^{2}$ squares with a grid. Thirteen coordinate locations were randomly generated, and the experimenter visited each of those in turn. Upon arrival in the middle of the pre-determined square, they closed their eyes and spun around. After opening their eyes, they took the pebble or stone closest to their right foot, provided it was smaller than or equal to the largest stone other subjects had interacted with in the past (Fig. 3). If it was bigger than the largest stone any of the kea had interacted with during observation sessions, the procedure was repeated until an appropriately sized stone was sampled. This ensured that we did not select any disproportionately large stones or rocks, which not even subjects with complete beaks would have been able to hold. Their surface areas were then measured digitally from photographs to compare Bruce's pebble selections to a random subset of those available in the aviary.

Video coding and analyses. Video data was coded using BORIS v.7.9.15 [Behavioral Observation Research Interactive Software $]^{51}$. Behaviours were classed using a purpose-designed ethogram (Supplementary Table 2). Preening episodes were defined as lengths of time where the subject repeatedly touched their beak to any part of their body and ended when there was no beak contact for $>30 \mathrm{~s}$. All observations were coded by one experimenter, while a second experimenter independently coded a random $10 \%$ sample of all recorded observations. Inter-coder agreement between experimenters was high for both stages, both in terms of preening behaviours and object manipulations (Supplementary Table 3).

To assess whether Bruce's pebble manipulations co-occurred with preening, we used a Bayesian contingency table test with a Poisson sample distribution to compare his object manipulation frequency when object manipulation occurred alone or concurrently with preening. Second, we investigated whether the thirteen pebble tools selected by Bruce and recovered by the experimenters were deliberately selected for their properties by comparing their sizes to those of thirteen randomly selected pebbles from across the aviary, with a Bayesian independent samples t-test. We also assessed the frequency and duration of Bruce's preening of different body parts with and without a pebble across a subset of observations where we could identify which body part was being preened. The frequency data were analyzed by a Bayesian contingency table test with a Poisson sample distribution. The duration was analyzed by a Bayesian paired samples t-test. Finally, we directly compared the 
objects manipulated by Bruce to those manipulated by other individuals using a Bayesian independent samples $\mathrm{t}$-test. All main analyses were carried out in JASP v.0.14.1.0 $0^{52}$ using default priors and all t-tests were two-sided.

\section{Data availability}

Original data created for the study will be available on the following online repository upon publication: https:// osf.io/j2sdn/.

Received: 30 March 2021; Accepted: 27 July 2021

Published online: 10 September 2021

\section{References}

1. Fragaszy, D. M. \& Mangalam, M. Tooling. Adv. Study Behav. 50, 177-241 (2018).

2. Fragaszy, D. M. \& Mangalam, M. Folks physics in the twenty-first century: Understanding tooling as embodied. Anim. Behav. Cogn. 7, 457-473 (2020).

3. Shumaker, R. W., Walkup, K. R. \& Beck, B. B. Animal Tool Behavior: The Use and Manufacture of Tools by Animals (Johns Hopkins University Press, 2011).

4. Hunt, G. R., Gray, R. D. \& Taylor, A. H. Why is tool use rare in animals. In Tool Use in Animals: Cognition and Ecology 89-118 (Cambridge University Press, 2013).

5. Cabrera-Âlvarez, M. J. \& Clayton, N. S. Neural processes underlying tool use in humans, macaques, and corvids. Front. Psychol. 11, 2486 (2020).

6. Ramsey, G., Bastian, M. L. \& van Schaik, C. P. Animal innovation defined and operationalized. Behav. Brain Sci. 30, 407-432 (2007).

7. Emery, N. J. \& Clayton, N. S. Tool use and physical cognition in birds and mammals. Curr. Opin. Neurobiol. 19, 27-33 (2009).

8. Lefebvre, L., Reader, S. M. \& Sol, D. Brains, innovations and evolution in birds and primates. Brain Behav. Evol. 63, 233-246 (2004).

9. Bentley-Condit, V. K. \& Smith, E. O. Animal tool use: Current definitions and an updated comprehensive catalog. Behaviour 147, 185-221 (2010).

10. Boire, D., Nicolakakis, N. \& Lefebvre, L. Tools and brains in birds. Behaviour 139, 939-973 (2002).

11. Hunt, G. R. Manufacture and use of hook-tools by New Caledonian crows. Nature 379, 249-251 (1996).

12. Lefebvre, L., Whittle, P., Lascaris, E. \& Finkelstein, A. Feeding innovations and forebrain size in birds. Anim. Behav. 53, 549-560 (1997).

13. Gruber, R. et al. New Caledonian crows use mental representations to solve metatool problems. Curr. Biol. 29, 686-692.e3 (2019).

14. Hunt, G. R. \& Gray, R. D. Species-wide manufacture of stick-type tools by New Caledonian crows. Emu 102, 349-353 (2002)

15. Rutz, C. et al. Discovery of species-wide tool use in the Hawaiian crow. Nature 537, 403-407 (2016).

16. Taylor, A. H., Elliffe, D., Hunt, G. R. \& Gray, R. D. Complex cognition and behavioural innovation in New Caledonian crows. Proc. R. Soc. B Biol. Sci. 277, 2637-2643 (2010).

17. Taylor, A. H., Hunt, G. R. \& Gray, R. D. Context-dependent tool use in New Caledonian crows. Biol. Lett. 8, 205-207 (2012).

18. Weir, A. S., Chapell, J. \& Kacelnik, A. Shaping of hooks in New Caledonian crows. Science (80-.) 297, 981-981 (2002).

19. Auersperg, A. M. I., Szabo, B., Von Bayern, A. M. P. \& Kacelnik, A. Spontaneous innovation in tool manufacture and use in a Goffin's cockatoo. Curr. Biol. 22, R903-R904 (2012).

20. Borsari, A. \& Ottoni, E. B. Preliminary observations of tool use in captive hyacinth macaws (Anodorhynchus hyacinthinus). Anim. Cogn. 8, 48-52 (2005).

21. Goodman, M., Hayward, T. \& Hunt, G. R. Habitual tool use innovated by free-living New Zealand kea. Sci. Rep. 8, 1-12 (2018).

22. Heinsohn, R., Zdenek, C. N., Cunningham, R. B., Endler, J. A. \& Langmore, N. E. Tool-assisted rhythmic drumming in palm cockatoos shares key elements of human instrumental music. Sci. Adv. 3, e1602399 (2017).

23. Lambert, M. L., Seed, A. M. \& Slocombe, K. E. A novel form of spontaneous tool use displayed by several captive greater vasa parrots (Coracopsis vasa). Biol. Lett. 11, 20150861 (2015).

24. Weir, A. S. \& Kacelnik, A. A New Caledonian crow (Corvus moneduloides) creatively re-designs tools by bending or unbending aluminium strips. Anim. Cogn. 9, 317-334 (2006).

25. Kacelnik, A., Chappell, J., Kenward, B. \& Weir, A. S. Cognitive adaptations for tool-related behaviour in New Caledonian Crows. In Comparative Cognition: Experimental Explorations of Animal Intelligence 515-528 (Oxford University Press, 2006).

26. Auersperg, A. M. I., Gajdon, G. K. \& Huber, L. Kea, Nestor notabilis, produce dynamic relationships between objects in a secondorder tool use task. Anim. Behav. 80, 783-789 (2010).

27. Auersperg, A. M. I., von Bayern, A. M. P., Gajdon, G. K., Huber, L. \& Kacelnik, A. Flexibility in problem solving and tool use of kea and New Caledonian crows in a multi access box paradigm. PLoS ONE 6, e20231 (2011).

28. Fayet, A. L., Hansen, E. S. \& Biro, D. Evidence of tool use in a seabird. Proc. Natl. Acad. Sci. 117, 1277-1279 (2020).

29. McGrew, W. C. Is primate tool use special? Chimpanzee and new Caledonian crow compared. Philos. Trans. R. Soc. B Biol. Sci. 368, 20120422 (2013).

30. Janzen, D. H., Pond, M. \& C. ,. Too-using by the African Grey Parrot (Psittacus erithacus). Biotropica 8, 70 (1976).

31. Auersperg, A. M. I., Schwing, R., Mioduszewska, B., O’Hara, M. \& Huber, L. Do puffins use tools?. Proc. Natl. Acad. Sci. 117, 11859 (2020).

32. Dechaume-Moncharmont, F.-X. Touchy matter: The delicate balance between Morgan's canon and open-minded description of advanced cognitive skills in the animal. Peer Community Ecol. 1, 100042 (2020).

33. Farrar, B. Evidence of tool use in a seabird? PsyArXiv (2020).

34. Sándor, K. \& Miklósi, Á. How to report anecdotal observations? A new approach based on a lesson from "puffin tool use”. Front. Psychol. 11, 2620 (2020).

35. von Bayern, A. M. P., Jacobs, I. \& Osvath, M. Tool-using puffins prickle the puzzle of cognitive evolution. Proc. Natl. Acad. Sci. 117, 2737-2739 (2020).

36. Clayton, D. H. et al. Adaptive significance of avian beak morphology for ectoparasite control. Proc. R. Soc. B Biol. Sci. 272, $811-817$ (2005).

37. Auersperg, A. M. I., Huber, L. \& Gajdon, G. K. Navigating a tool end in a specific direction: stick-tool use in kea (Nestor notabilis). Biol. Lett. 7, 825-828 (2011).

38. Werdenich, D. \& Huber, L. A case of quick problem solving in birds: String pulling in keas, Nestor notabilis. Anim. Behav. 71, 855-863 (2006).

39. Auersperg, A. M. I., Gajdon, G. K. \& Huber, L. Kea (Nestor notabilis) consider spatial relationships between objects in the support problem. Biol. Lett. 5, 455-458 (2009).

40. Bastos, A. P. M. \& Taylor, A. H. Kea (Nestor notabilis) represent object trajectory and identity. Sci. Rep. 9, 1-9 (2019).

41. Heaney, M., Gray, R. D. \& Taylor, A. H. Keas perform similarly to chimpanzees and elephants when solving collaborative tasks. PLoS ONE 12, e0169799 (2017).

42. Huber, L. \& Gajdon, G. K. Technical intelligence in animals: The kea model. Anim. Cogn. 9, 295-305 (2006). 
43. Bastos, A. P. M. \& Taylor, A. H. Kea show three signatures of domain-general statistical inference. Nat. Commun. 11, 1-8 (2020).

44. Gajdon, G. K., Lichtnegger, M. \& Huber, L. What a parrot's mind adds to play: The urge to produce novelty fosters tool use acquisition in Kea. Open J. Anim. Sci. 04, 51-58 (2014).

45. Lambert, M. L. et al. Function and flexibility of object exploration in kea and new Caledonian crows. R. Soc. Open Sci. 4, 170652 (2017).

46. Taylor, A. H. \& Gray, R. D. Is there a link between the crafting of tools and the evolution of cognition?. Wiley Interdiscip. Rev. Cogn. Sci. 5, 693-703 (2014).

47. Teschke, I., Cartmill, E. A., Stankewitz, S. \& Tebbich, S. Sometimes tool use is not the key: No evidence for cognitive adaptive specializations in tool-using woodpecker finches. Anim. Behav. 82, 945-956 (2011).

48. Bird, C. D. \& Emery, N. J. Insightful problem solving and creative tool modification by captive nontool-using rooks. Proc. Natl. Acad. Sci. 106, 10370-10375 (2009).

49. Miller, R. et al. Decision-making flexibility in New Caledonian crows, young children and adult humans in a multi-dimensional tool-use task. PLoS ONE 15, e0219874 (2020)

50. Heaney, M., Bastos, A. P. M., Gray, R. D. \& Taylor, A. H. Are kea prosocial?. Ethology 126, 176-184 (2020).

51. Friard, O. \& Gamba, M. BORIS: A free, versatile open-source event-logging software for video/audio coding and live observations. Methods Ecol. Evol. 7, 1325-1330 (2016).

52. JASP Team. JASP Version 0.14.1.0. (2019).

\section{Acknowledgements}

This project was made possible through the support of a grant from Templeton World Charity Foundation (AHT), a Rutherford Discovery Fellowship (AHT), and a Prime Minister's McDiarmid Emerging Scientist Prize (AHT). It was also supported by the UNKP-20-3 New National Excellence Program of the Ministry for Innovation and Technology from the source of the National Research, Development and Innovation Fund (KH). We thank the Willowbank Wildlife Reserve and its staff, particularly Nick Ackroyd and Kirsty Willis, for their continued support of our research and allowing the use of the park's captive kea population.

\section{Author contributions}

A.P.M.B. conceived the study; all authors designed the study; A.P.M.B., K.H., J.W., and P.M.W. collected the data; K.H. and P.M.W. coded the video data; A.P.M.B., K.H., J.W., and P.M.W. analyzed the data; A.P.M.B. wrote the original manuscript; all authors were involved in reviewing the manuscript.

\section{Competing interests}

The authors declare no competing interests.

\section{Additional information}

Supplementary Information The online version contains supplementary material available at https://doi.org/ 10.1038/s41598-021-97086-w.

Correspondence and requests for materials should be addressed to A.P.M.B.

Reprints and permissions information is available at www.nature.com/reprints.

Publisher's note Springer Nature remains neutral with regard to jurisdictional claims in published maps and institutional affiliations.

Open Access This article is licensed under a Creative Commons Attribution 4.0 International License, which permits use, sharing, adaptation, distribution and reproduction in any medium or format, as long as you give appropriate credit to the original author(s) and the source, provide a link to the Creative Commons licence, and indicate if changes were made. The images or other third party material in this article are included in the article's Creative Commons licence, unless indicated otherwise in a credit line to the material. If material is not included in the article's Creative Commons licence and your intended use is not permitted by statutory regulation or exceeds the permitted use, you will need to obtain permission directly from the copyright holder. To view a copy of this licence, visit http://creativecommons.org/licenses/by/4.0/.

(C) The Author(s) 2021 